\title{
DESENVOLVIMENTO E PRODUTIVIDADE DE CULTIVARES DE ARROZ DE TERRAS ALTAS EM FUNÇÃO DO MANEJO DO SOLO ${ }^{1}$
}

\author{
Adriano Stephan Nascente ${ }^{2}$, João Kluthcouski², Raimundo Ricardo Rabelo ${ }^{2}$, \\ Priscila de Oliveira ${ }^{3}$, Tarcísio Cobucci ${ }^{2}$, Carlos Alexandre Costa Crusciol ${ }^{4}$
}

\section{ABSTRACT \\ UPLAND RICE CULTIVARS DEVELOPMENT \\ AND YIELD REGARDING SOIL MANAGEMENT}

The identification of upland rice cultivars for each kind of soil management system can increase upland rice yield. So, this study aimed to evaluate upland rice genotypes under two soil management systems: conventional tillage (CT) and no-tillage (NT). The experiment was carried out in Ipameri, Goiás State, Brazil, in 2008/2009. A randomized blocks design, in a $2 \times 8$ factorial scheme, with sixteen treatments and four replications was used. The first factor was the soil management system (CT and NT) and the second one rice genotypes (BRS Curinga, BRS Primavera, BRS Monarca, BRS Pepita, BRS Sertaneja, Carajás, Caiapó, and Bonança). Plants grew higher under CT than NT. For number of tillers per plant, there were differences among rice cultivars, according to the soil management system. For yield, CT provided higher rates (average of 4,349 $\mathrm{kg} \mathrm{ha}^{-1}$ ) than NT (average of 3,521 $\mathrm{kg} \mathrm{ha}^{-1}$ ), being the number of panicles $\mathrm{m}^{-2}$ and number of grains panicle ${ }^{-1}$ the yield components responsible for that difference. All cultivars presented statistic differences between the two soil management systems, except for the Caiapó cultivar. For both systems, Carajás reached the highest yield, differing from the BRS Sertaneja and BRS Primavera cultivars.

KEY-WORDS: Oryza sativa; no-tillage system; moldboard plow; yield.

\section{INTRODUÇÃO}

$\mathrm{O}$ arroz constitui fonte importante de calorias e proteínas, na dieta alimentar (Arf et al. 2001). Devido a estas características nutricionais, este alimento pode contribuir para a melhoria da nutrição e qualidade de vida do brasileiro (Santos et al. 2006), por ser uma cultura que apresenta grande adaptabilidade às mais variadas condições de solo e clima, caracterizando

\section{RESUMO}

A identificação de cultivares, para cada tipo de manejo do solo, pode favorecer o aumento da produtividade da cultura do arroz de terras altas. Neste contexto, objetivou-se, com este trabalho, estudar o desempenho de genótipos de arroz de terras altas, em dois sistemas de manejo do solo: preparo convencional (PC) e sistema plantio direto (SPD). O estudo foi desenvolvido no município de Ipameri, GO, em 2008/2009. O delineamento experimental foi em blocos ao acaso, no esquema fatorial $2 \mathrm{x} 8$, com dezesseis tratamentos e quatro repetições. $\mathrm{O}$ primeiro fator foi o sistema de manejo do solo (PC e SPD) e o segundo cultivares (BRS Curinga, BRS Primavera, BRS Monarca, BRS Pepita, BRS Sertaneja, Carajás, Caiapó e Bonança). As plantas apresentaram-se mais altas no PC do que no SPD. Quanto ao número de perfilhos por planta, verificou-se, também, variabilidade nas cultivares, quanto ao tipo de manejo de solo. Constatou-se que o preparo convencional propiciou maiores produtividades (média de $4.349 \mathrm{~kg} \mathrm{ha}^{-1}$ ) que o sistema plantio direto (média de $3.521 \mathrm{~kg} \mathrm{ha}^{-1}$ ), sendo o número de panículas por $\mathrm{m}^{2}$ e número de grãos por panícula os componentes de produção que mais contribuíram para esta diferença. Todas as cultivares apresentaram diferenças estatísticas entre os dois sistemas de manejo do solo, com exceção da cultivar Caiapó. Nos dois sistemas, Carajás foi a mais produtiva e diferiu, estatisticamente, das cultivares BRS Sertaneja e BRS Primavera.

PALAVRAS-CHAVE: Oryza sativa; sistema plantio direto; arado de aiveca; produtividade.

grande potencial de aumento de produtividade. Dentre os fatores a serem aperfeiçoados, para aumentar a produtividade da cultura, está o manejo do solo. Esta operação é realizada visando a propiciar condições satisfatórias para a semeadura, germinação de sementes, emergência de plântulas, desenvolvimento, produtividade, eliminação de plantas daninhas, controle de erosão e descompactação do solo (Silva \& Moreira 2006). A opção do sistema de manejo do solo varia

1. Trabalho recebido em ago./2009 e aceito para publicação em jan./2011 (nº registro: PAT 6980/ DOI: 10.5216/pat.v41i2.6980).

2. Embrapa Arroz e Feijão, Departamento Técnico-Científico, Santo Antônio de Goiás, GO, Brasil.

E-mails: adriano@cnpaf.embrapa.br, joaok@cnpaf.embrapa.br, raimundo@cnpaf.embrapa.br, cobucci@cnpaf.embrapa.br.

3. Universidade de São Paulo, Escola Superior de Agricultura Luiz de Queiroz, Departamento de Fitotecnia, Piracicaba, SP, Brasil.E-mail: poliveira@esalq.usp.br.

4. Universidade Estadual Paulista, Faculdade de Ciências Agronômicas, Departamento de Agricultura, Botucatu, SP, Brasil. E-mail: crusciol@fca.unesp.br. 
com a textura, estrutura e grau de compactação do solo, bem como de acordo com a disponibilidade de equipamentos e de recursos do produtor.

De acordo com a Embrapa (1992), os principais sistemas de manejo do solo empregados para o cultivo do arroz em terras altas são: arado de disco, grade aradora (mais utilizada na região dos Cerrados), aração invertida (incorporação da resteva com grade, seguida de aração profunda com arado de aiveca), preparo mínimo e sistema plantio direto. Dentre estes, o manejo do solo com arado de discos, com grade aradora e aração invertida são considerados preparos convencionais do solo.

O preparo convencional do solo (PC) é o mais utilizado para o arroz e vem trazendo melhores resultados de produtividade do que o sistema plantio direto (SPD) (Stone et al. 1980, Seguy \& Bouzinac 1992, Kluthcouski et al. 2000). Isto pode ocorrer devido à exigência da cultura, em solos com maior macroporosidade, ou à demanda inicial por nitrogênio, na forma amoniacal, sendo, portanto, muito sensível à qualidade do perfil do solo (Seguy et al. 1989, Seguy \& Bouzinac 1992, Kluthcouski et al. 2000).

O SPD, entretanto, é uma realidade brasileira, tendo ocupado, na safra 2005/2006, área aproximada de 25 milhões de hectares, dos quais cerca de $40 \%$ encontram-se em áreas dos Cerrados (Febrapdp 2009). Este sistema traz uma série de benefícios ambientais, como a diminuição da densidade populacional de plantas daninhas, redução da remoção de partículas do solo, diminuição da perda de fertilizantes e pesticidas, e, consequentemente, menor poluição das águas superficiais (Fornarolli et al. 1998, Vidal et al. 1998, Wietholter et al. 1998). Além disto, vem crescendo a demanda pela utilização do arroz, neste sistema, visando a mais uma opção para o produtor rural, no esquema de rotação de culturas com soja e milho.

Segundo Guimarães et al. (2002), as cultivares respondem diferentemente ao ambiente, com relação à produtividade de grãos. Além disto, ainda existem poucos estudos sobre o comportamento de cultivares em ambiente SPD. Neste sentido, este trabalho teve como objetivo avaliar o desempenho de genótipos de arroz de terras altas sob Cerrado, em dois sistemas de manejo do solo (preparo convencional e sistema plantio direto).

\section{MATERIAL E MÉTODOS}

O experimento foi desenvolvido no ano agrícola 2008/2009, na Fazenda Santa Brígida, no município de Ipameri, região sul do Estado de Goiás (17 $7^{\circ} 43^{\prime} 19^{\prime \prime} \mathrm{S}, 48^{\circ} 09^{\prime} 36^{\prime \prime} \mathrm{W}$ e altitude aproximada de $764 \mathrm{~m})$. O clima da região é classificado como tropical de altitude, Cwa, segundo Köppen. A temperatura média é de $25^{\circ} \mathrm{C}$, com umidade relativa média do ar variando de $58 \%$ a $81 \%$ e precipitação pluviométrica anual de $1.750 \mathrm{~mm}$, sendo que cerca de $80 \%$ das chuvas ocorrem nos meses de dezembro, janeiro e março e o restante se distribui, principalmente, nos meses de outubro, novembro e fevereiro. Devido à inexistência de instrumentos de coleta de variáveis climáticas na Fazenda Santa Brígida, utilizou-se o balanço hídrico mensal do município de Ipameri (GO), como forma de caracterização climática da Região (Figura 1). O solo é classificado como Latossolo Vermelho distrófico típico, segundo a atual nomenclatura do Sistema Brasileiro de Classificação de Solos (Embrapa 2006), apresentando textura argilosa (Tabela 1) e tendo sido cultivado, anteriormente, com Brachiaria brizantha (a área estava sob pastagem há mais de 10 anos). $\mathrm{O}$ solo da área de cultivo caracterizou-se por apresentar baixa fertilidade (Tabela 2).

$\mathrm{O}$ delineamento experimental foi em blocos ao acaso, em esquema fatorial $2 \times 8$, com dezesseis tratamentos e quatro repetições. $\mathrm{O}$ primeiro fator correspondeu ao sistema de manejo do solo ( $\mathrm{PC} \mathrm{e}$

Tabela 1. Composição granulométrica do solo da área experimental (Ipameri, GO, 2008).

\begin{tabular}{rcccc}
\hline \multirow{3}{*}{ Profundidade } & \multicolumn{3}{c}{ Textura } & Classificação \\
\cline { 2 - 4 } & $\begin{array}{rccc}\text { Argila } & \text { Silte } & \text { Areia } & \\
\text { textural }\end{array}$ \\
\hline $\mathrm{g} \mathrm{kg}^{-1}$ & $\mathrm{~g} \mathrm{~kg}^{-1}$ & $\mathrm{~g} \mathrm{~kg}^{-1}$ & \\
\hline $0-0,10 \mathrm{~m}$ & 569 & 100 & 331 & Argiloso \\
$0,10-0,20 \mathrm{~m}$ & 569 & 120 & 311 & Argiloso \\
$0,20-0,40 \mathrm{~m}$ & 589 & 120 & 291 & Argiloso \\
\hline
\end{tabular}

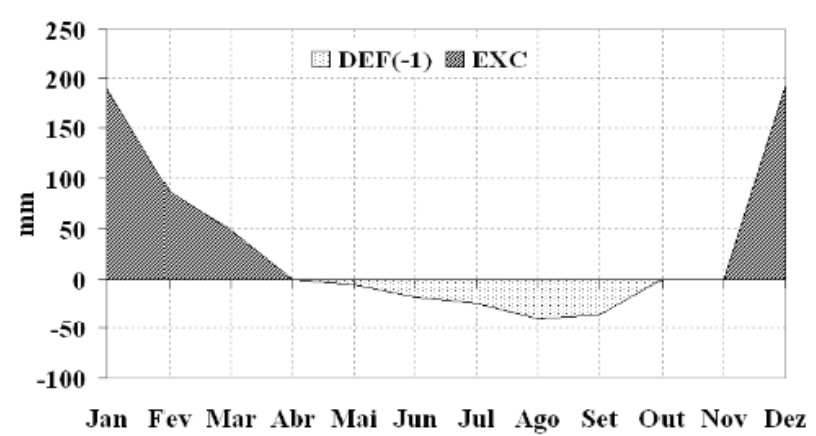

Figura 1. Balanço hídrico mensal do município de Ipameri, GO (Sentelhas et al. 2010). 
Tabela 2. Características químicas do solo da área experimental (Ipameri, GO, 2008).

\begin{tabular}{|c|c|c|c|c|c|c|c|c|c|c|c|c|}
\hline \multirow{3}{*}{ Profundidade } & \multicolumn{12}{|c|}{ Atributos químicos } \\
\hline & $\mathrm{pH}$ & $\mathrm{Ca}$ & $\mathrm{Mg}$ & $\mathrm{Al}$ & $\mathrm{H}+\mathrm{Al}$ & $\mathrm{P}$ & $\mathrm{K}$ & $\mathrm{Cu}$ & $\mathrm{Zn}$ & $\mathrm{Fe}$ & $\mathrm{Mn}$ & \multirow{2}{*}{$\frac{\text { M.O. }}{\mathrm{g} \mathrm{dm}^{-3}}$} \\
\hline & $\mathrm{H}_{2} \mathrm{O}$ & \multicolumn{4}{|c|}{$\mathrm{cmol}_{\mathrm{c}} \mathrm{dm}^{-3}$} & \multicolumn{6}{|c|}{$\mathrm{mg} \mathrm{dm}^{-3}$} & \\
\hline $0-0,10 \mathrm{~m}$ & 5,4 & 1,26 & 0,43 & 0,1 & 5,30 & 3,2 & 100 & 2,8 & 5,1 & 40 & 20 & 21 \\
\hline $0,10-0,20 \mathrm{~m}$ & 5,4 & 1,71 & 0,64 & 0,1 & 5,34 & 9,0 & 97 & 3,0 & 6,0 & 41 & 23 & 19 \\
\hline $0,20-0,40 \mathrm{~m}$ & 5,5 & 1,08 & 0,46 & 0,1 & 4,80 & 2,1 & 87 & 2,9 & 3,2 & 38 & 18 & 17 \\
\hline
\end{tabular}

SPD) e o segundo foi composto por cultivares de arroz de terras altas (BRS Curinga, BRS Primavera, BRS Monarca, BRS Pepita, BRS Sertaneja, Carajás, Caiapó e BRS Bonança). As parcelas experimentais constituíram-se por 7 linhas de arroz, com 5 metros de comprimento, espaçadas $0,45 \mathrm{~m}$ entre si, sendo a parcela útil composta pelas duas linhas centrais.

O preparo convencional do solo (PC) foi realizado com arado de aiveca, 15 dias antes da semeadura, seguido de uma gradagem niveladora, no dia da semeadura. No SPD, a dessecação da cultura antecessora (Brachiaria brizantha) foi realizada 30 dias antes da semeadura, com o herbicida glyphosate, na dose de $1,8 \mathrm{~kg} \mathrm{ha}^{-1}$ de equivalente ácido (e.a.).

Parte da adubação nitrogenada foi realizada antecipadamente, 1 dia antes da semeadura, na dose de $67,5 \mathrm{~kg} \mathrm{~N} \mathrm{ha}^{-1}$, na forma de ureia, incorporada com adubadora. A semeadura foi realizada no dia 25/11/2008, com densidade de 100 sementes por m, utilizando-se semeadora-adubadora com espaçamento entre linhas de $0,45 \mathrm{~m}$ (cinco linhas por passada). A adubação básica do sulco de semeadura foi constituída por $400 \mathrm{~kg} \mathrm{ha}^{-1}$ da fórmula $08-20-15$. As sementes foram tratadas com inseticida à base de carbofuran (Furazin $310 \mathrm{FS}$ ), à dose de $2 \mathrm{~L}$ do produto comercial para $100 \mathrm{~kg}$ de sementes $\left(310 \mathrm{~g} \mathrm{~L}^{-1}\right)$. Os tratos culturais nas cultivares foram realizados de acordo com a necessidade da cultura. Não foi realizada irrigação e nem adubação de cobertura.

As operações de ceifa, trilha e limpeza dos grãos foram realizadas manualmente. A medição de umidade e a pesagem foram realizadas em sequência e a massa final corrigida para $13 \%$ de umidade. Foram avaliadas as seguintes características: estande (com o uso de uma régua de $1 \mathrm{~m}$, contaram-se todas as plantas neste comprimento, aos 10 dias após a emergência da cultura, nas 2 linhas centrais); altura de plantas (com o uso de uma régua, mediram-se 10 plantas ao acaso, em cada parcela); perfilhamento (contou-se o número de perfilhos de 10 plantas escolhidas ao acaso, nas duas linhas centrais das parcelas); componentes de produção (número de panículas por $\mathrm{m}^{-2}$, número de grãos por panícula e massa de 1.000 grãos, com coleta de 10 plantas ao acaso, nas duas linhas centrais, para avaliar estas variáveis); e produtividade, selecionando-se as duas linhas centrais das parcelas e desprezando-se os primeiros $50 \mathrm{~cm}$ de cada extremidade. Os grãos foram pesados e a umidade ajustada para $13 \%$ e transformada para $\mathrm{kg} \mathrm{ha}^{-1}$. Todos os efeitos dos tratamentos foram avaliados por meio de análise de variância e teste comparativo de médias Tukey (5\%), utilizando-se o programa estatístico Sisvar.

Com relação aos componentes de produção, foram coletados dados em apenas uma repetição, escolhida ao acaso. Assim, estas variáveis (número de panículas $\mathrm{m}^{-2}$, número de grãos panícula ${ }^{-1}$ e massa de 1.000 grãos, resultantes da coleta de 10 plantas ao acaso, nas duas linhas centrais) foram analisadas por meio de estatística descritiva, estimando-se a média geral, desvio-padrão, coeficiente de variação e amplitude total (limites máximo e mínimo), referentes a cada característica, em cada sistema de manejo, seguindo metodologia semelhante à proposta por Nascente (2003).

\section{RESULTADOS E DISCUSSÃO}

Pelos resultados obtidos nas condições experimentais, verificou-se que, para a característica altura de plantas, de modo geral, o preparo convencional (PC) propiciou maior crescimento das plantas do que o sistema plantio direto (SPD), sendo a altura máxima, no $\mathrm{PC}$, de $119 \mathrm{~cm}$, com a cultivar Caiapó, e, no SPD, de $110 \mathrm{~cm}$, com a cultivar BRS Sertaneja (Tabela 3), com média do PC de $107 \mathrm{~cm}$ de altura e, no SPD, de $100 \mathrm{~cm}$. Comparando-se as cultivares, segundo o mesmo manejo de solo, verificou-se que, no PC, a BRS Bonança apresentou a menor altura $(93 \mathrm{~cm})$, diferindo, estatisticamente, de todas as outras cultivares, com exceção da BRS MG Curinga. Em SPD, a cultivar BRS MG Curinga apresentou 
Tabela 3. Avaliação da altura de plantas $(\mathrm{cm})$, número de perfilhos por planta e produtividade de cultivares de arroz de terras altas sob Cerrado, em dois sistemas de manejo do solo: preparo convencional (PC) e sistema plantio direto (SPD) (Ipameri, GO, 2008/2009).

\begin{tabular}{|c|c|c|c|c|c|c|}
\hline \multirow{2}{*}{$\begin{array}{l}\text { Característica } \\
\text { Tratamentos }\end{array}$} & \multicolumn{2}{|c|}{ Altura de plantas $(\mathrm{cm})$} & \multicolumn{2}{|c|}{ Perfilhos por planta } & \multicolumn{2}{|c|}{ Produtividade $\left(\mathrm{kg} \mathrm{ha}^{-1}\right)$} \\
\hline & $\mathrm{PC}$ & SPD & $\mathrm{PC}$ & SPD & $\mathrm{PC}$ & SPD \\
\hline \multicolumn{7}{|l|}{ Cultivar } \\
\hline Carajás & $106 \mathrm{ab} \mathrm{A} *$ & 99 bc A & $224 \mathrm{abc} A$ & $244 \mathrm{ab} A$ & $4.896 \mathrm{a} A$ & 3.866 a B \\
\hline Caiapó & 119 a A & 115 a B & $224 \mathrm{abc} A$ & $240 \mathrm{ab} A$ & $4.204 \mathrm{abc} \mathrm{A}$ & $3.870 \mathrm{a} \mathrm{A}$ \\
\hline BRS Sertaneja & 112 a A & $110 \mathrm{ab} \mathrm{A}$ & $180 \mathrm{~d} A$ & 196 c A & $3.879 \mathrm{bc} \mathrm{A}$ & $3.153 \mathrm{~b} \mathrm{~B}$ \\
\hline BRS Primavera & 110 a A & $101 \mathrm{bc} \mathrm{B}$ & $236 \mathrm{ab} \mathrm{A}$ & 196 c B & 3.748 c A & $3.093 \mathrm{~b} \mathrm{~B}$ \\
\hline BRS Pepita & $107 \mathrm{ab} \mathrm{A}$ & $97 \mathrm{~cd} \mathrm{~B}$ & $212 \mathrm{bcd} A$ & $228 \mathrm{ab} A$ & $4.446 \mathrm{abc} A$ & $3.436 \mathrm{ab} \mathrm{B}$ \\
\hline BRS Monarca & 112 a A & $101 \mathrm{bc} \mathrm{B}$ & 208 bcd A & 196 c A & $4.396 \mathrm{abc} \mathrm{A}$ & $3.636 \mathrm{ab} \mathrm{B}$ \\
\hline BRS MG Curinga & 96 bc A & 85 d B & 260 a A & 260 a A & $4.672 \mathrm{ab} A$ & $3.676 \mathrm{ab} \mathrm{B}$ \\
\hline BRS Bonança & $93 \mathrm{c} \mathrm{A}$ & $90 \mathrm{~cd} \mathrm{~A}$ & $200 \mathrm{~cd} \mathrm{~A}$ & $212 \mathrm{bc} \mathrm{A}$ & $4.550 \mathrm{abc} \mathrm{A}$ & $3.438 \mathrm{ab} \mathrm{B}$ \\
\hline Média & 107 & 100 & 218 & 222 & 4.349 & 3.521 \\
\hline CV (\%) & 5,01 & 5,89 & 7,0 & 10,19 & 8,22 & 7,56 \\
\hline
\end{tabular}

* Médias seguidas da mesma letra minúscula, na vertical, e maiúscula, na horizontal, não diferem entre si, pelo teste Tukey, a $5 \%$.

menor altura $(85 \mathrm{~cm})$, porém, não diferiu, estatisticamente, da BRS Bonança e BRS Pepita. Desta forma, verificou-se que houve interação das cultivares com o método de manejo do solo, pois algumas cultivares cresceram mais no PC (Caiapó, BRS Primavera, BRS Pepita, BRS Monarca e BRS MG Curinga) e outras não diferiram entre si (Carajás, BRS Sertaneja e BRS Bonança), nos dois sistemas de manejo do solo.

Verificou-se que, de maneira geral, o preparo convencional favoreceu o maior crescimento das plantas e a maior altura. Possivelmente, este tipo de preparo propiciou melhor desenvolvimento do sistema radicular, aproveitando melhor a água e nutrientes, resultando em plantas mais desenvolvidas. Segundo Arf et al. (2001), em solos não compactados, as plantas apresentam melhor desenvolvimento radicular, o que, normalmente, se traduz em aumento de produtividade. A média de altura para as cultivares, no PC, foi de $107 \mathrm{~cm}$, valor próximo ao obtido por Arf et al. (2001), que, trabalhando com arado de aiveca, obtiveram média de altura de $109 \mathrm{~cm}$. Esta característica é importante, pois cultivares de porte alto e colmo fraco podem acamar mais facilmente, principalmente quando recebem doses altas de nitrogênio, uma vez que este nutriente estimula o desenvolvimento foliar e o crescimento das plantas.

O acamamento diminui a seção transversal dos feixes vasculares, portanto, reduz o movimento dos fotoasssimilados e dos nutrientes absorvidos pelas raízes e, em consequência, diminui a produtividade do arroz (Guimarães et al. 2002). Além disto, aumenta o autosombreamento, contribuindo para maior esterilidade de grãos. Por outro lado, colmos mais curtos facilitam a respiração e aumentam o aproveitamento dos produtos fotossintéticos. Entretanto, o porte extremamente baixo é desvantajoso, porque induz ao aumento do autosombreamento. Portanto, a planta deve ter um porte intermediário, para resistir ao acamamento e apresentar menor autosombreamento (Fageria 1989).

Para a variável número de perfilhos por planta, verificou-se variabilidade nas cultivares, quanto ao tipo de manejo de solo. A média foi superior no SPD, com 222 perfilhos por planta, enquanto, no PC, a média foi de 218 (Tabela 3). Nos dois tipos de manejo do solo, a cultivar BRS MG Curinga se destacou, apresentando o maior valor, em comparação com a BRS Pepita, BRS Monarca, BRS Bonança e BRS Sertaneja, no preparo convencional, e com a BRS Bonança, BRS Monarca, BRS Primavera e BRS Sertaneja, no SPD (Tabela 3). Comparando-se as cultivares, nos dois sistemas de manejo do solo, somente a BRS Primavera diferiu estatisticamente, quanto a esta característica, mostrando interação dos dois tipos de manejo. Segundo Yoshida (1981), genótipos perfilhadores apresentam vantagem, por se adaptarem a vários espaçamentos e densidades de semeadura, e, ainda, compensarem a semeadura irregular.

Constatou-se que o preparo convencional proporcionou maiores produtividades (média de $4.349 \mathrm{~kg} \mathrm{ha}^{-1}$ ) do que o sistema plantio direto (média de $3.521 \mathrm{~kg} \mathrm{ha}^{-1}$ ). Todas as cultivares apresentaram di- 
ferenças estatísticas entre os dois sistemas de manejo do solo, com exceção da cultivar Caiapó (Tabela 3). Nos dois sistemas, a cultivar Carajás foi a que obteve maior produtividade de grãos, em comparação com as cultivares BRS Sertaneja e BRS Primavera. A produtividade da Carajás foi superior no $\mathrm{PC}$, em relação ao SPD, com mais de uma tonelada de grãos (Tabela 3).

Este aumento na produtividade do arroz de terras altas no PC, em relação ao SPD, pode ser explicado, principalmente, pelo aumento no número de panículas por $\mathrm{m}^{2}$ (12\% superior) e número de grãos panícula $^{-1}$ (20\% superior) (Tabela 4$)$.

A produtividade média $\left(4.349 \mathrm{~kg} \mathrm{ha}^{-1}\right)$ no PC foi superior à obtida por Arf et al. (2001), que observaram média de $3.419 \mathrm{~kg} \mathrm{ha}^{-1}$, nos tratamentos onde o solo foi preparado com arado de aiveca. Segundo Guimarães et al. (2006), as cultivares respondem diferentemente ao ambiente, com relação à produtividade de grãos. Com o SPD, obteve-se produtividade de $3.521 \mathrm{~kg} \mathrm{ha}^{-1}$, média superior à da Região Centro-Oeste, que foi de $2.932 \mathrm{~kg} \mathrm{ha}^{-1}$, na safra 2008/2009 (Conab 2009). Assim, verificou-se que a produtividade no SPD, apesar de inferior ao PC, foi quase $20 \%$ superior à média da Região, mostrando que a tecnologia utilizada permite rendimentos satisfatórios, sob condições de Cerrado.

Comparando-se a produtividade das cultivares, nos dois sistemas, verificou-se que o preparo convencional possibilitou maior produtividade a todas as cultivares, com exceção da cultivar Caiapó, que apresentou produtividade semelhante nos dois sistemas (Tabela 3). Este resultado é similar ao obtido por Kluthcouski et al. (2000), que avaliaram o desen- volvimento de cultivares de arroz em vários sistemas de manejo do solo e observaram que, em SPD, os materiais apresentaram menor média de produtividade de grãos, com redução de $31,55 \%$, em relação aos demais manejos. De acordo com estes autores, a cultura do arroz é sensível à baixa porosidade do solo, corroborando os resultados encontrados por Seguy \& Bouzinac (1992), que relataram ser esta gramínea bastante sensível à condição de baixa macroporosidade no solo, fato que, segundo Guimarães \& Moreira (2001), causa redução no desenvolvimento da parte aérea e radicular das plantas de arroz, com o aumento da densidade do solo. Stone et al. (1980) e Guimarães et al. (2002) também obtiveram maiores produtividades de grãos de arroz, no sistema de preparo de solo convencional (arado de aiveca). Assim, verificou-se que, apesar de já ser possível conseguir boas produtividades na cultura do arroz, no sistema plantio direto, ainda é necessário desenvolver tecnologias para que o arroz tenha melhor desempenho, quando comparado com o sistema convencional.

Quanto aos componentes de produção, verificou-se que, no SPD, a cultivar Caiapó apresentou produtividade de grãos, número de panículas por $\mathrm{m}^{2}$, grãos por panícula e \% de grãos viáveis superiores à média do ensaio, com destaque para o número de panículas por $\mathrm{m}^{2}$ (Tabela 4). Esta característica, juntamente com grãos panícula ${ }^{-1}$, apresentou as maiores amplitudes, com valores de 90-121 panículas $\mathrm{m}^{-2} \mathrm{e}$ 124-171 grãos panícula ${ }^{-1}$. Segundo Guimarães et al. (2002), estas variáveis correlacionam-se diretamente com a produtividade. Assim, especial atenção deve ser dada ao manejo da cultura do arroz, no sentido de se maximizarem estes valores.

Tabela 4. Avaliação dos componentes de produção de cultivares de arroz de terras altas sob Cerrado, nos sistemas plantio direto (SPD) e plantio convencional com arado de aiveca (PC) (Ipameri, GO, 2008/2009).

\begin{tabular}{lrrrrrrrr}
\hline \multirow{2}{*}{ Cultivares } & \multicolumn{2}{c}{ Panículas $\mathrm{m}^{-2}$} & \multicolumn{2}{c}{ Grãos panícula ${ }^{-1}$} & \multicolumn{2}{c}{ \% grãos viáveis } & \multicolumn{2}{c}{ Peso 1.000 grãos (g) } \\
\cline { 2 - 8 } & SPD & PC & SPD & PC & SPD & PC & SPD & PC \\
\hline BRS Bonança & 108 & 132 & 143 & 163 & 84,16 & 81,25 & 26,37 & 26,09 \\
BRS MG Curinga & 121 & 143 & 152 & 145 & 77,93 & 84,98 & 25,76 & 26,58 \\
BRS Monarca & 90 & 102 & 167 & 218 & 80,56 & 78,14 & 29,94 & 25,37 \\
BRS Pepita & 92 & 98 & 171 & 238 & 86,95 & 78,63 & 25,13 & 24,40 \\
BRS Primavera & 91 & 108 & 139 & 168 & 83,56 & 77,87 & 29,23 & 26,59 \\
BRS Sertaneja & 95 & 103 & 159 & 173 & 77,69 & 80,51 & 27,02 & 27,17 \\
Caiapó & 107 & 99 & 168 & 201 & 84,51 & 84,03 & 25,50 & 25,27 \\
Carajás & 99 & 113 & 124 & 144 & 95,14 & 90,99 & 33,17 & 33,05 \\
\hline Média & 100 & 112 & 153 & 181 & 84 & 82 & 28 & 27 \\
\hline Desvio Padrão & 10.77 & 16.58 & 16.60 & 34.19 & 5.62 & 4.47 & 2.80 & 2.67 \\
\hline CV (\%) & 10.77 & 14.8 & 10.85 & 18.89 & 6.71 & 5.45 & 9.99 & 9.9 \\
\hline Valores máximos & 121 & 143 & 171 & 238 & 95.14 & 90.99 & 33.17 & 33.05 \\
\hline Valores mínimos & 90 & 98 & 124 & 144 & 77.69 & 77.87 & 25.13 & 24.40 \\
\hline
\end{tabular}


No PC, a cultivar Carajás apresentou amplitudes para as características panículas $\mathrm{m}^{-2}$ (98 a 143) e grãos panícula-1 ${ }^{-1}(144$ a 238), bem como para os seus respectivos desvios-padrões, bem superiores ao SPD (Tabela 4), mostrando que este tipo de sistema de manejo do solo (PC) parace ser mais instável, sendo necessários maiores cuidados para se evitar redução nestas características tão importantes para a produtividade do arroz.

Segundo Veiga et al. (2010), o SPD é um sistema mais estável, que possibilita maiores benefícios ambientais, como o aumento da atividade biológica do solo, pela menor amplitude de temperatura e maior conservação da umidade, e menores oscilações de $\mathrm{pH}$, reduzindo a remoção de partículas do solo e diminuindo a perda de fertilizantes e agrotóxicos. Observou-se, também, que a cultivar Carajás, que teve uma das maiores produtividade de grãos, destacou-se na viabilidade dos grãos e na massa de 1.000 sementes, fato ocorrido, para esta característica, nos dois tipos de preparo do solo, com valores superiores a 33 gramas (Tabela 4).

\section{CONCLUSÕES}

1. A cultivar Carajás foi mais produtiva do que as cultivares BRS Sertaneja e BRS Primavera, nos dois sistemas de manejo do solo.

2. A cultivar Caiapó apresentou produtividade semelhante, nos dois sistemas de manejo do solo.

3. O preparo convencional do solo apresentou maiores amplitudes de variação nos componentes de produção panículas $\mathrm{m}^{-2}$ e grãos panícula ${ }^{-1}$ que o sistema plantio direto

4. As cultivares de arroz, com exceção da Carajás, apresentaram melhor desempenho no preparo convencional do que no sistema plantio direto.

\section{REFERÊNCIAS}

ARF, O. et al. Resposta de cultivares de arroz de sequeiro ao preparo do solo e à irrigação por aspersão. Pesquisa Agropecuária Brasileira, Brasília, DF, v. 36, n. 6, p. 871879, 2001.

\section{COMPANHIA NACIONAL DE ABASTECIMENTO} (Conab). Acompanhamento de safra brasileira: grãos: safra 2008/2009, oitavo levantamento, maio/2009. 2009. Disponível em: <http://www.conab.gov.br/conabweb/ download/safra/8graos_08.09.pdf > . Acesso em: 18 ago. 2009.
EMPRESA BRASILEIRA DE PESQUISA AGROPECUÁRIA (Embrapa). Serviço de Produção de Informação. Recomendações técnicas para o cultivo do arroz em regiões favorecidas: zonas 31, 36, 40, 64, 83 e 89. Brasília, DF: Embrapa, 1992.

EMPRESA BRASILEIRA DE PESQUISA AGROPECUÁRIA (Embrapa). Sistema brasileiro de classificação de solos. Rio de Janeiro: Embrapa/CNPSo, 2006.

FAGERIA, N. K. Solos tropicais e aspectos fisiológicos das culturas. Brasília, DF: Embrapa-DPU, 1989.

FEDERAÇÃO BRASILEIRA DE PLANTIO DIRETO NA PALHA (Febrapdp). Evolução da área cultivada no sistema de plantio direto na palha - Brasil. 2009. Disponível em: <http://www.febrapdp.org.br/arquivos/ EvolucaoAreaPDBr72A06.pdf>. Acesso em: 18 ago. 2009.

FORNAROLLI, D. A. et al. Influência da cobertura morta no comportamento do herbicida atrazine. Planta Daninha, Londrina, v. 16, n. 2, p. 97-107, 1998.

GUIMARÃES, C. M.; MOREIRA, J. A. A. Compactação do solo na cultura do arroz de terras altas. Pesquisa Agropecuária Brasileira, Brasília, DF, v. 36, n. 4, p. 703707, 2001.

GUIMARÃES, C. M; FAGERIA, N. K.; BARBOSA FILHO, M. P. Como a planta de arroz se desenvolve. Piracicaba: Potafos, 2002. (Arquivo do agrônomo, 13).

GUIMARÃES, C. M.; STONE, L. F.; CASTRO, E. da M. de. Comportamento de cultivares de arroz de terras altas no sistema plantio direto em duas profundidades de adubação. Bioscience Journal, Uberlândia, v. 22. n. 1, p. 53-59, 2006.

KLUTHCOUSKI, J. et al. Manejo do solo e o rendimento de soja, milho, feijão e arroz em plantio direto. Scientia Agricola, Piracicaba, v. 57, n. 1, p. 97-104, 2000.

NASCENTE, A. S. Caracterização morfológica de progênies nativas de guariroba (Syagrus oleracea becc.) no Estado de Goiás. Pesquisa Agropecuária Tropical, Goiânia, v. 33, n. 2, p. 113-115, 2003.

SANTOS, A. B. dos; STONE, L. F.; VIEIRA, N. R. de A. (Eds.). A cultura do arroz no Brasil. 2. ed. rev. ampl. Santo Antônio de Goiás: Embrapa Arroz e Feijão, 2006.

SEGUY, L.; BOUZINAC, S. Arroz de sequeiro na Fazenda Progresso: $4550 \mathrm{~kg} / \mathrm{ha}$. Informações Agronômicas, Piracicaba, n. 58, p. 1-3, 1992.

SEGUY, L.; BOUZINAC, S. R. P.; PACHECO, A. Perspectiva de fixação da agricultura na região centronorte do Mato Grosso. Mato Grosso: EMPA-MT/ Embrapa-CNPAF/CIRAD-IRAT, 1989.

SENTELHAS, P. C. et al. (Orgs.). BHBRASIL: balanços hídricos climatológicos de 500 localidades brasileiras. 2010. Disponível em: <http://www.leb.esalq.usp.br/ bhbrasil/Goias/>. Acesso em: 15 abr. 2010. 
SILVA, J. G. da; MOREIRA. J. A. A. Preparo do Solo. In: SANTOS, A. B. dos; STONE, L. F.; VIEIRA, N. R. de A. (Eds.). A cultura do arroz no Brasil. 2. ed. rev. ampl. Santo Antônio de Goiás: Embrapa Arroz e Feijão, 2006. p. 359-386.

STONE, L. F.; SANTOS, A. B. dos; STEINMETZ, S. Influência de práticas culturais na capacidade de retenção de água do solo e no rendimento do arroz-de-sequeiro. Pesquisa Agropecuária Brasileira, Brasília, DF, v. 15, n. 1, p. 63-68, 1980.

VEIGA, M. et al. Tillage systems and nutrient sources affecting soil cover, temperature and moisture in a clayey Oxisol under corn. Revista Brasileira de Ciência do Solo, Viçosa, v. 34, n. 6, p. 2011-2020, 2010.
VIDAL, R. A. et al. Palha no sistema de semeadura direta reduz a infestação de gramíneas anuais e aumenta a produtividade da soja. Ciência Rural, Santa Maria, v. 28, n. 3, p. 373-377, 1998.

WIETHOLTER, S. et al. Fósforo e potássio no solo no sistema plantio direto. In: NUERNBERG, N. J. (Ed.). Conceitos e fundamentos do sistema plantio direto. Lages: Sociedade Brasileira de Ciência do Solo, 1998. p. 121-149.

YOSHIDA, S. Fundamentals of rice crop science. Los Baños: IRRI, 1981. 